\title{
El rol de la felicidad ajena en la filosofía práctica de Kant
}

\author{
[The Role of the Happiness of Others in Kant's Practical Philosophy]
}

\author{
MACARENA MAREY \\ Universidad de Buenos Aires \\ Consejo Nacional de Investigaciones Científicas y Técnicas \\ macarenamarey@gmail.com
}

\begin{abstract}
Resumen: En este trabajo, presento e intento resolver un problema que la oposición de Kant al eudaimonismo podría plantear al segundo deber de virtud. Tras analizarlo, propondré que el deber de la felicidad ajena consigue disolver al menos uno de los obstáculos para alcanzar la felicidad en la Tierra (la felicidad propia empírica anhelada naturalmente por los seres humanos en cuanto seres racionales y finitos). El motivo de esto es que el deber de promover los fines de los demás logra reubicar la felicidad hedónica en el plano de la moralidad, algo que la noción intelectual de felicidad como componente del bien supremo no consigue hacer y en esto consiste el rol que el deber de la felicidad ajena cumple en el sistema ético kantiano.
\end{abstract}

Palabras clave: eudaimonismo, racionalidad finita, anhelo natural, segundo deber de virtud, beneficencia

\begin{abstract}
The aim of this paper is to introduce and try to solve a problem Kant's opposition to eudemonism could pose to the second duty of virtue. After analysing this problem, I hold that the duty to promote the happiness of others dissolves at least one of the obstacles one faces when striving to achieve one's own happiness on Earth, which we naturally desire as finite rational beings. Unlike the intellectual notion of happiness implied by the concept of the highest good, the duty to promote the happiness of others places hedonic happiness within the realm of morality. This is, I propose, the fundamental role the second duty of virtue plays in Kant's ethical system.

Key words: eudemonism, finite rationality, natural longing, second duty of virtue, beneficence
\end{abstract}

\section{Introducción}

Una de las notas salientes de la filosofía práctica de Kant es su escepticismo respecto de la capacidad de seres racionales finitos como nosotros para conseguir la felicidad. Nos encontramos en diversos pasajes del corpus kantiano con afirmaciones como la siguiente: "Si sigue la máxima de la felicidad, la voluntad titubea, entre sus móviles, lo que debe decidir; pues mira hacia el éxito y él es muy incierto; se necesita de una buena cabeza para desovillar el embrollo de razones a favor y en contra para no engañarse a sí mismo en el cálculo final" (TP, 287; 
las traducciones de las obras de Kant citadas son mías). Las incontables observaciones pesimistas de Kant respecto de la capacidad de la razón para conducirnos a nuestra felicidad no son meras afirmaciones antropológicas aisladas. Se insertan en el marco más amplio de la tarea filosófica de refutar el eudaimonismo fundacional en filosofía práctica, i.e., la tesis de que la felicidad propia pueda funcionar como fuente de normatividad. Esta tarea se incluye, a su vez, en el programa kantiano de refutar cualquier teleologismo normativo, incluido el perfeccionismo, $\mathrm{y}$ el objetivo de tal refutación es el de sostener la tesis positiva de que nuestra libertad práctica incluye la facultad de proponernos a nosotros mismos los fines que queramos para nuestras acciones y para nuestra vida. El tópico de la felicidad resulta todavía más importante en la filosofía kantiana en cuanto que todos los principios y fines materiales (heterónomos) que se clasifican en la tabla del $\S 8$ de la Crítica de la razón práctica "son, como tales, en su conjunto de un único y mismo tipo y pertenecen al principio general del amor propio o de la felicidad propia" $(K p V, 22)$. Por lo demás, las críticas de Kant al eudaimonismo normativo no se limitan al campo de la ética. También son parte fundamental de su filosofía política. En Teoría y praxis Kant afirma que el principio de la felicidad "ocasiona el mal también en el derecho estatal tanto como lo hace en la moral", pues "el soberano quiere hacer feliz al pueblo de acuerdo con sus conceptos y se convierte en déspota; el pueblo no se quiere privar del derecho universal a su propia felicidad y se vuelve rebelde" (TP, 302).

Sin embargo, la oposición de Kant al eudaimonismo no implica que renuncie a encontrar un lugar para la felicidad dentro de su filosofía práctica. Kant reubica la felicidad (y la perfección) en el sistema metafísico de la moral. La felicidad se convierte en uno de los dos fines que son al mismo tiempo deberes bajo la forma de la felicidad ajena y también se introduce bajo la rúbrica del concepto de "ser digno de ser feliz" en la idea del "bien supremo". Además, si bien es claro que por "felicidad" Kant entiende principalmente la satisfacción de las inclinaciones en un todo organizado y el contento presente y futuro con ello, aparece en su obra la noción de felicidad moral e intelectual. La polisemia de la felicidad en Kant se encuentra paradigmáticamente ya en el tratamiento de la idea de bien supremo en la "Segunda sección del canon de la razón pura". Allí, aparece una de las definiciones de la felicidad "empírica": "La felicidad es la satisfacción de todas nuestras

${ }^{1} \mathrm{Cfr} . \mathrm{KpV}, 40$, "Fundamentos prácticos materiales de determinación en el principio de la moralidad".

Diánoia, vol. LXII, no. 78 (mayo de 2017). 
inclinaciones (tanto extensivamente, de la multiplicidad de ellas, como intensivamente, según el grado, y también protensivamente, según la duración)" ( $K r V$, B 834). Y sin embargo, cuando se trata de la idea de felicidad repartida de manera acorde al merecimiento moral, en este mismo lugar Kant afirma que la felicidad que merecemos si hacemos lo que debemos no hemos de esperarla en nuestra vida. Es decir que en el concepto mismo de "bien supremo" por el que Kant intenta resolver la cuestión de la esperanza que está ligada inseparablemente a la felicidad, ${ }^{2}$ la felicidad terrenal definida en los términos empíricos de las inclinaciones queda conceptualmente desplazada por la idea de una felicidad merecida en un mundo que es "para nosotros futuro [...] posible sólo en un mundo inteligible" ( $K r V$, B 839).

Así, es evidente que al tratar el tópico de la felicidad deberemos esperar una serie de complejidades conceptuales y semánticas que dan forma a una serie de problemas filosóficos. En este trabajo, quisiera detenerme en un problema en particular. El problema que quisiera delimitar e intentar resolver puede ser resumido como sigue: si la crítica de Kant al principio o fin de la felicidad propia es, como sostendré, radical y lo lleva a negar cualquier posibilidad de que ella se convierta en una guía confiable para la acción, ¿cómo es posible que ella pueda guiar nuestra conducta a la hora de cumplir con el deber de la felicidad ajena, tal como es tratado en la Doctrina de la virtud? Mi tesis central respecto de la crítica de Kant al principio de la felicidad propia es que si bien existe un uso de la razón por el cual no andamos a tientas cuando intentamos ser felices, esto es, que quizás podamos sortear con las fuentes kantianas la indeterminabilidad absoluta del concepto de la felicidad propia, su problematicidad no puede ser salvada a la hora de implementar este concepto en el mundo. Esto plantea un problema normativo para la doctrina kantiana de la virtud. Como sabemos, la felicidad propia no es un deber, pero sí lo es promover la felicidad ajena. Si la felicidad ajena es un deber, tiene que ser posible cumplir con él; tendríamos que poder hacer felices a los demás, pues ultra posse nemo obligatur. La pregunta que se plantea es: ¿por qué la felicidad ajena puede guiar la praxis moral, si se trata en definitiva de la misma felicidad empírica que, cuando es propia, no nos provee una regla fiable práctica? ¿Qué hace que la felicidad propia, cuando es de los otros, sea capaz de guiar mi voluntad sin (tantos) titubeos?

\footnotetext{
${ }^{2}$ Kant afirma que "todo esperar [Hoffen] se encamina a la felicidad" ( $\mathrm{KrV}$, B 833).
} 
Mi respuesta comienza con la simple indicación de que el deber de la felicidad de los otros seres humanos nos demanda, además de tener una "benevolencia activa" (MS, 452) y "participar activamente de sus destinos" (MS, 457), proponérnoslos como nuestros fines. Proponernos a los demás seres humanos como fines implica reconocerlos como fines en sí mismos, ${ }^{3}$ pero además como "semejantes, como seres racionales necesitados", con quienes estamos "reunidos por la naturaleza en una morada para la ayuda recíproca" ( $M S, 453$, las cursivas son mías). Este reconocimiento moral de la condición racional y al mismo tiempo menesterosa de los demás consigue reubicar la felicidad empírica en un sistema de moralidad que depende de nuestra voluntad, pero sin dejar de considerar esa felicidad como empírica y nacida del anhelo natural de ser felices, algo que no puede lograrse con la noción intelectual de felicidad. Si bien esto no subsana de manera absoluta los obstáculos que la naturaleza nos pone en la búsqueda de la felicidad, sí logra abrir una esperanza concreta para la felicidad empírica, aquí y ahora, por medio de la asistencia mutua de las personas en esa búsqueda. Éste es el rol que la felicidad ajena juega en el sistema práctico kantiano. ${ }^{4}$

${ }^{3}$ Esto no implica bajo ningún punto de vista que en este trabajo yo trate el problema de la felicidad en el marco de la formulación del imperativo categórico en los términos de la humanidad como fin. Ésa no es la estrategia que sigue Kant en la Doctrina de la virtud y por lo tanto me resulta inadecuado y necesario de mucha justificación cualquier intento por hacerlo. También resulta injustificado presentar objeciones en tales términos a la argumentación que desarrollaré aquí; hacerlo demandaría una argumentación ulterior que muestre la pertinencia de tal línea de contraargumentación (la carga de la prueba no la tiene mi trabajo en esta oportunidad). Agradezco al segundo dictaminador de Diánoia por instarme a aclarar este punto, dado que la mención del vocablo "humanidad" puede prestarse a confusión o a conclusiones apresuradas si no se conoce la Metafísica de las costumbres en profundidad ni la literatura especializada. Dicho de otro modo, cuando Kant habla de la humanidad como fin no siempre tiene en mente la formulación del imperativo categórico en esos términos que había presentado en la Fundamentación. Antes bien, deberíamos pensar en el "principio supremo de la doctrina de la virtud" tal cual él es formulado en $M S$, 395. Asimismo, como se verá más adelante, es imposible sostener que con la así (mal) llamada "fórmula de la humanidad" sea posible derivar un deber moral de la felicidad propia. Kant es explícito al respecto ( $M S$, 387-388 es un lugar textual central, no marginal, en el que afirma y explica esto muy claramente). En ese caso se trataría de perfección propia y, así, por más argumentos que quieran presentarse al respecto, hay una respuesta kantiana simple: se trata de otro deber, a saber, de la perfección propia, no de felicidad propia, y en todo caso se trata de un uso impropio de la palabra "Glückseligkeit".

${ }^{4}$ Agradezco al primer dictaminador de Diánoia que me haya instado a aclarar, si bien no es necesario para quien conoce las fuentes kantianas pertinentes, que sí 
En la sección 2, discutiré con la idea, propuesta polémicamente por David Gauthier y recientemente defendida por Ji Young Kang, de que la felicidad empírica propia tiene alguna capacidad para convertirse en

existe en Kant un deber de hacer felices a las demás personas y que la felicidad de la que trata este deber de virtud o de obligación amplia es empírica en el sentido que le doy en este trabajo, siguiendo a Kant: por "felicidad empírica" se entiende una felicidad "física", por contraposición a "moral", que se define grosso modo como la satisfacción de las inclinaciones y el contento con ello. Que Kant trate esta noción en términos de los fines que las demás personas se proponen bajo tal concepto de "felicidad" no modifica en nada mis posturas y argumentos; de hecho, mi postura central se basa en tal indicación. Si bien vuelvo sobre lo específico de este deber de virtud en varias oportunidades en este trabajo, digamos aquí que Kant no sólo denomina expresamente al deber-fin o deber amplio en cuestión "felicidad ajena" (fremde Glückseligkeit), sino que además define el contenido de este deber de esta manera: "Por lo tanto, cuando se trata de aquella felicidad que debe ser un deber promover como fin mío, tiene que ser entonces la felicidad de otros seres humanos, con lo cual yo convierto también en mi[s] fin [es] su[s] fin [es] (permitido[s])" (MS, 388: "Wenn es also auf Glückseligkeit ankommt, worauf, als meinem Zweck, hinzuwirken es Pflicht sein soll, so muß es die Glückseligkeit anderer Menschen sein, derer (erlaubten) Zweck ich hiemit auch zu dem meinigen mache"). Asimismo, uno de los criterios para la descarga de este deber amplio no es simplemente que no ponga en peligro la felicidad propia, sino que no contradiga normativamente el deber de la perfección propia. De nuevo, Kant lo dice explícitamente en $M S, 388$ a renglón seguido de la cita recién mencionada; abundar en el tema más allá de la claridad de las fuentes puede resultar en un ejercicio de glosa muy poco ameno.

Por otro lado, que este deber sea exlcusivo de la ética e imposible de traducir en un correlato político es claro también para todo aquel que conozca la obra de Kant: los deberes de virtud o fines que son deberes jamás pueden estar acompañados de coacción, jamás pueden convertirse en deberes jurídicos. Kant es explícito al respecto en toda su obra práctica y sobre la prohibición kantiana de convertir un "deber de virtud" en fuente de derecho positivo no puede caber la menor duda. No es una objeción seria, por lo tanto, que si se puede de hecho hacer felices a los demás seres humanos entonces un déspota tendría derecho a hacerlo. Tal cosa no es permisible no sólo porque no se puede traducir un deber de virtud en fuente de leyes jurídicas, sino que además se violaría la prohibición de imponer fines a los demás (prohibición que comparten la ética y el derecho en Kant). Lo que un déspota quiere -en esto Kant es tan claro que no hace falta argumentar más allá de remitir a las fuentes- no es hacer felices a sus "súbditos" según sus propios fines, quiere imponerles ideas de la felicidad que no son de ellos. Kant es explícito al respecto: "Aquí es evidente que el principio de la felicidad [...] ocasiona el mal también en el derecho estatal tanto como lo hace en la moral [...]. El gobernante quiere hacer feliz al pueblo de acuerdo con sus conceptos [i.e., del gobernante] y se convierte en déspota; el pueblo no se quiere privar del derecho universal a su propia felicidad y se vuelve rebelde" (TP, 302, las cursivas son mías). Glosemos, aunque no sea realmente necesario: el déspota no quiere hacer felices a los demás, no está cumpliendo con ninguna lectura rigurosa del segundo deber de virtud; el 
una guía práctica certera de la conducta. Respecto de la polisemia de "felicidad" en el corpus kantiano, resaltaré que Kant no renuncia nunca a la idea de que la felicidad a la que se refiere nuestro anhelo natural es terrenal. La sección 3 está dedicada a analizar el deber de la felicidad ajena en la Doctrina de la virtud.

\section{La felicidad propia}

El núcleo conceptual de la crítica moral de Kant a la felicidad propia como candidata a erigirse en fuente de normatividad y guía práctica consiste en que un fin natural prefijado no haría sino quitarnos una parte fundamental de nuestra libertad, aquella que proviene de nuestra capacidad de proponernos a nosotros mismos nuestros propios fines inmediatos y a largo plazo. Ahora bien, esto no quiere decir que los seres humanos puedan renunciar sin más a la felicidad en la Tierra. En la "Observación II" al "Teorema II" (§ 3) de la "Analítica de los principios", encontramos que la razón principal de esto es que la felicidad no es innata, no es algo que ya tengamos, sino algo a buscar. Al mismo tiempo, la felicidad propia es un fin al que nuestra disposición natural como seres racionales finitos no nos permite renunciar. El conocido pasaje establece que:

Ser feliz es necesariamente el anhelo de todo ser racional pero finito y por lo tanto un fundamento de determinación ineludible de su facultad de apetecer. Pues el contento con su existencia entera no es algo así como una posesión originaria ni una beatitud que presuponga una conciencia de la propia autosuficiencia independiente, sino que es un problema que se le impone por su propia naturaleza finita, porque es menesteroso y esta

déspota eudaimonista quiere negarles a las personas su derecho a ser felices como les plazca al imponerles su propio (el del déspota) ideal privado de felicidad. No se trata, así, de ninguna instancia seria del segundo deber de virtud. Un caso paradigmático de la imposibilididad moral de traducir un deber ético en fuente de derecho positivo está en $R G V, 95-96$. Cito in extenso: "En una comunidad política existente todos los ciudadanos políticos qua ciudadanos políticos se encuentran en el estado de naturaleza ético y están autorizados a permanecer en él. Pues sería una contradicción in adiecto que una comunidad política coaccionara a sus ciudadanos para hacerlos ingresar en la condición ética, porque ésta conlleva en su concepto el estar libre de coacción [... ] /96/iAy del legislador que quiera concretar por medio de la coacción una constitución orientada a fines éticos! Pues no sólo estaría realizando directamente lo contrario de una constitución ética, sino que también estaría socavando su constitución política y volviéndola insegura". También agradezco al primer dictaminador por haberme instado a traer a colación este punto, trivial para la Kant-Forschung, pero que quizás necesite de aclaración por fuera de ella. 
necesidad atañe a la materia de su facultad de apetecer, es decir, es algo que remite a un sentimiento de placer o displacer que está subjetivamente en la base y por el cual se determina lo que se necesita para el contento con su estado. $(\mathrm{KpV}, 25)$

La tesis de que la felicidad es un anhelo que necesariamente tenemos como seres racionales finitos implica, a mi entender, dos puntos fundamentales. El primero de ellos atañe al rol que juega la razón respecto de la consecución de la felicidad. ${ }^{5}$ Aquí, se plantean dos preguntas:

${ }^{5}$ La singularidad irreductible del concepto de felicidad propia, es decir, que cada persona tenga una representación diferente de ella, se debe asimismo a que se trata de un "ideal de la imaginación" (GMS , 418). Por citas como ésta, se podría sostener, como sugiere Kienzle (2007, p. 273), que la razón no juega el rol principal en la construcción del concepto de felicidad, pues "si [la felicidad] fuera un ideal de la razón [y no de la imaginación], entonces cada ser racional colocaría su felicidad en exactamente lo mismo". Ahora bien, Kant afirma también que la búsqueda de la felicidad propia empírica es "una misión irrenunciable de la razón" ( $K p V, 61$, las cursivas son mías). Asimismo, Kant sostiene (en el mismo pasaje en el que se dice que la felicidad es un ideal de la imaginación) que "la idea de la felicidad" es la idea de "un todo absoluto, un máximo del bienestar, en mi estado presente y futuro" (GMS, 418). Al respecto, Kang nota correctamente que "los conceptos de un todo representan la unidad sistemática completa pensada por la razón, algo que un ser racional finito sólo puede buscar alcanzar aproximadamente. Según las reflexiones de Kant, 'construir ideas' es una propiedad esencial de la razón de ir de lo condicionado a la totalidad" (Kang 2015, p. 23), y esto es precisamente lo que ocurre con la elaboración de nuestros conceptos de felicidad propia en cuanto conceptos de una totalidad que no es reductible a la mera agregación de sus partes aisladas.

En el corpus kantiano, encontramos apoyo textual tanto para sostener que el concepto de en qué se cifra nuestra felicidad propia es un ideal elaborado por la imaginación como para sostener que la razón (en alguno de sus usos, principalmente, en un uso prudencial) es la encargada de elaborar este fin. Sin pronunciarme acerca de esta ambigüedad aparente (es en realidad una suerte de antinomia), me concentraré en el rol de la razón en alguno de sus usos respecto de la felicidad porque podemos proponernos de manera deliberada el fin de la felicidad como propósito de nuestras acciones a cuenta de que tenemos una razón práctica, i.e., no porque tengamos la facultad de la imaginación. Asimismo, intentaré mostrar que el hecho de que la razón (por contraposición al instinto) sea la encargada de procurar la felicidad propia es lo que justifica la tesis kantiana acerca de que la felicidad hedónica no es alcanzable. Ello motiva pasajes como aquel en el que Kant afirma que la razón tiene la "osadía de figurarse para sí misma, con sus débiles conocimientos, el proyecto de la felicidad y de los medios para alcanzarla" (GMS, 395). En rigor, esta osadía de la razón es inevitable desde el momento en que la felicidad propia no nos es dada por naturaleza, mientras que sí nos es dado el anhelo de ser felices en la Tierra. 
acerca del modo en que la razón, en alguno de sus usos, elabora una concepción de en qué se cifra la concepción particular de la felicidad de cada persona, y cómo se relaciona nuestra razón con nuestra condición menesterosa. El segundo punto atañe al hecho de que si la felicidad es un anhelo ineludible, necesariamente tiene que tener un lugar en la moral, so pena de que la moral kantiana resulte insensible a un rasgo esencial de nuestra condición humana. Aquí parecería entrar en juego el concepto de un bien supremo con el que Kant responde la tercera pregunta del "Canon": "si hago lo que debo, ¿qué me es permitido esperar?" (KrV, B 834). ${ }^{6}$ Analizaré en lo que sigue la primera de estas cuestiones para luego abocarme a la segunda. Al revisar las nociones de felicidad moral y felicidad intelectual, mi objetivo es recordar que ni la felicidad ligada al merecimiento ni la felicidad moral consiguen satisfacer nuestro anhelo natural de ser felices.

\subsection{El problema de los medios para alcanzar el fin de ser felices}

En un polémico artículo de 1985, Gauthier se propuso mostrar que dada su concepción hedonista de la felicidad, Kant debería haber sostenido que la razón sí puede emplear la felicidad como un principio práctico. ${ }^{7}$

${ }^{6}$ A partir de la hipótesis básica de que la ética kantiana no puede prescindir de la felicidad propia, dado que ella es un anhelo natural inevitable, el recomendable libro de Rivera Castro (2014) se dedica a precisar el rol que cumple en la ética de Kant entendida a partir de la Fundamentación de la metafísica de las costumbres. La autora parte de la tesis de que el entero carácter categórico de la moralidad kantiana se basa en el merecimiento de la felicidad y, por lo tanto, encuentra que la felicidad queda garantizada en el concepto de bien supremo según es tratado en la primera Crítica. Aquí sostendré que el rol sistemático de la felicidad en cuanto componente del bien supremo no es el de satisfacer el anhelo de ser felices empíricamente, dado que se trata de una felicidad intelectual, no de la felicidad definida en términos hedonistas. Trato este tópico más adelante.

${ }^{7}$ Darwall (1985) respondió al texto de Gauthier. Su estrategia para refutar la lectura gauthieriana es la misma que aplica Gauthier para mostrar que la razón kantiana puede ser entendida bajo los términos de la teoría de la elección racional (esto es, que se puede justificar la cooperación exclusivamente en términos egoístas). Darwall muestra que los presupuestos gauthierianos conducen a la necesidad de postular una moral (basada en el cumplimento de pactos) tal que entra en contradicción con el mismo egoísmo racional de los maximizadores globales. Por mi parte, como se verá en mi análisis de la postura de Kang (más erudita y cercana a las fuentes que la de Gauthier, quien no se propone una interpretación filológica de Kant), creo que se puede responder a la postura gauthieriana incluso concediendo que existe un uso prudencial de la razón en la elaboración del concepto de felicidad propia como fin, pero que este uso no subsana el problema de los medios que conducen a este fin. La diferencia entre la lectura de Gauthier —y la teoría de 
Gauthier intenta acercar a Kant a la teoría de la acción racional para sostener que Kant debería haber suscrito a la fundamentación de la cooperación en las motivaciones egoístas de agentes plenamente racionales (maximizadores globales). Su hipótesis interpretativa central es que

La negación de Kant de que la felicidad dé lugar a la ley práctica y su rechazo de cualquier rol distintivo para la razón en relación con la felicidad reflejan que no logró entender las implicaciones de su concepción de la felicidad como la satisfacción de todos nuestros deseos. Pues, así concebida, la felicidad no nos es dada como un objeto de deseo, sino que tiene que ser construida a partir de deseos particulares que surgen de nuestras necesidades. $^{8}$

A pesar de la paráfrasis imprecisa de la definición de "felicidad" (Kant no habla de "deseos", sino de "inclinaciones"), Gauthier no se aleja del último pasaje kantiano que he citado. En efecto, es correcto que la idea de la felicidad no nos es dada. Tenemos el anhelo universal de ser felices porque tenemos una condición menesterosa, pero el concepto de en qué se cifrará nuestra felicidad en particular no nos es dado ni de manera innata ni a priori. Así, es esperable que cada sujeto tenga un rol más o menos espontáneo (activo) en la determinación de qué es la felicidad. Podemos encontrar numerosas razones al respecto. Una de las

la elección racional en general-y Kant es que Kant no tiene tanta confianza en la eficacia práctica de la razón prudencial.

${ }^{8}$ Gauthier 1985, p. 78, las cursivas son mías. Es a todas luces evidente que yo no apoyo la lectura de Gauthier y Kang, sino que la critico. La argumentación que presento aquí intenta no hacer un straw man del adversario, por eso presento esta postura bajo su lectura más plausible. Agradezco al segundo dictaminador el haberme instado a explicitar esto. Mi trabajo no propone una lectura eudaimonista de Kant, tan sólo me propongo fijar el rol de la felicidad ajena en el marco problemático que plantea el mismo complejísimo concepto kantiano de felicidad. Claramente, mi lectura toma la moralidad como punto de partida y pone en cuestión la lectura de la línea Gauthier-Kang (si bien tomándola en serio) desde la perspectiva de la moralidad. Encuentro necesario tal ejercicio crítico porque es innegable que el tratamiento kantiano de la felicidad nos plantea más problemas que soluciones, más preocupaciones que razones para la tranquilidad, a quienes nos especializamos en la filosofía práctica de Kant, tengamos la interpretación que tengamos. Quizás podría afirmar que mi trabajo intenta no adoptar como verdadera ninguna interpretación de la ética de Kant, incluso la mía propia. Contraponer otra interpetación de la ética de Kant (cuya validez queda a cargo de quien contrapone demostrar) a la línea argumentativa que sigo para criticar la lectura de la línea Gauthier-Kang de la felicidad en Kant no afecta, en rigor de verdad, mi argumentación. 
principales se sigue precisamente del carácter empírico, contingente y a posteriori de la felicidad.

Kant afirma que "el concepto de felicidad" tiene una definición universal por la que siempre se remite a "la relación práctica de un sujeto con objetos de la facultad de apetecer", pero que esa definición general "no determina nada específico" $(K p V, 25)$. En efecto, "en qué cada uno haya de cifrar su felicidad depende de su sentimiento particular del placer o del displacer e incluso en el mismo sujeto depende de la diferencia de la necesidad según el cambio de este sentimiento" (KpV, 25). El hecho de que la felicidad sea "subjetivamente necesaria" (en cuanto anhelo ineludible para seres racionales sensibles y necesitados) se traduce en que "objetivamente" sea "un principio práctico muy contingente, que en diferentes sujetos puede y debe de ser muy diferente" $(K p V, 25)$. Sumados, los hechos de que la felicidad propia sea "subjetivamente necesaria" y que no nos sea dada de manera determinada implican que cada ser humano tenga que ser capaz de determinar su definición específica. En otras palabras, dado que no podemos renunciar al anhelo de ser felices y que al mismo tiempo no contamos a priori con el contenido del concepto de la felicidad propia, se vuelve necesario que cada sujeto realice alguna mediación racional entre las inclinaciones y necesidades que le vienen dadas desorganizadamente, por un lado, y la felicidad entendida como satisfacción de todas las inclinaciones, por el otro.

Es claro que Kant insiste en mostrar que la felicidad es esencialmente contingente y a posteriori para sostener que ella, en cuanto que está asociada a la agradabilidad en la sensibilidad, es incapaz de proveer reglas certeras que guíen nuestra conducta con algún grado aceptable de determinación y universalidad. No obstante esto, lo que quiero resaltar aquí es que, de manera algo paradójica, al mismo tiempo el carácter contingente y a posteriori de la felicidad es indicación de que es necesario que exista algún uso de la razón por el cual se dé forma al concepto particular de la felicidad propia. En el momento en que Kant define la felicidad como "satisfacción de todas las inclinaciones" (GMS, 399), esto es, en los términos de la satisfacción de un todo organizado cuya especificidad es irreductiblemente particular (hay una representación de la felicidad propia en cada sujeto práctico), se vuelve necesario que seamos capaces de producir este concepto nosotros mismos a partir de dos elementos dados de manera natural, v.gr., la multiplicidad de las inclinaciones y el anhelo de satisfacerlas. La necesidad de que lo seamos radica, nuevamente, en que no podemos renunciar al anhelo de ser felices. 
Como sabemos, satisfacer las inclinaciones para conseguir la felicidad propia no es equivalente a actuar en todo momento para satisfacer cualquier inclinación inmediata dada entre la multiplicidad de ellas. Kant consideraba que "la prescripción de la felicidad está constituida la mayor parte de las veces de modo tal que perjudica algunas inclinaciones" (GMS, 399). Yo puedo elegir por motivos hedonistas no satisfacer mi inclinación de pasear por las calles de Madrid, que resultaría en un sentimiento particular de agradabilidad para mí. Puedo elegir no satisfacer tal inclinación sin el motivo de la conciencia del deber, sino tomando otra inclinación como motivo impulsor, como por ejemplo mi inclinación particular de terminar de redactar un texto filosófico. Esto último me resultará particularmente agradable según mi concepto particular de la felicidad, suponiendo además que producir un texto filosófico no es un deber moral. Desde una perspectiva prudencial, este propósito me demanda realizar una serie de tareas que redundan en la postergación de un sinfín de otras inclinaciones. Así, hay una multiplicidad de inclinaciones particulares en mi sensibilidad que mi propio concepto de felicidad me conduce reflexivamente a postergar y declinar sólo porque existen otras inclinaciones, también particulares, a las que decido dar prioridad a la hora de su satisfacción.

Esto es lo que vuelve plausible, y de hecho cierta, una de las tesis que Gauthier presenta de manera polémica: que la razón tiene que jugar un rol en la elaboración de la felicidad propia. En su exhaustivo trabajo sobre la "felicidad universal", Kang también se concentra en analizar de qué modo elaboramos nuestros conceptos particulares de la felicidad propia a partir del material que nos provee nuestra sensibilidad. La tesis central de Kang es que es de hecho posible conseguir una guía práctica a partir de la felicidad, dado que ella es el producto de aplicar un imperativo de la prudencia para organizar nuestras necesidades e inclinaciones naturales en un todo cohesivo que es "constituido por la razón o por la imaginación". 9 Como Gauthier, Kang se basa en el hecho de que la felicidad propia es definida en términos hedonistas como "totalidad de las inclinaciones satisfechas" (cfr. GMS, 418 y KU, 430). Es correcto que la terminología de la "mayor satisfacción posible de las inclinaciones" nos autoriza a entender que "el agente le da forma al contenido de la felicidad por medio de su propia proposición de fines, al elegir entre sus inclinaciones algunas para satisfacer y otras para resignar" (Kang 2015, p. 18). El punto siguiente es cómo se produce este concepto de una totalidad. Al respecto, Kang sostiene que para elaborar

${ }^{9}$ Cfr. Kang 2015, p. 18. Véase la nota 5. 
su concepto particular de la felicidad, cada agente aplica "imperativos de la prudencia" que le permiten "determinar qué inclinaciones o bien qué necesidades quiere considerar como componentes de su concepción de la felicidad" (p. 18). El apoyo textual para esta lectura se encuentra innegablemente en el siguiente pasaje de la Religión dentro de los límites de la mera razón: "consideradas en sí mismas, las inclinaciones sensibles son buenas, esto es, inobjetables. [...] Sólo hay que controlarlas, más bien, para que no se aniquilen unas a otras y puedan convertirse en un todo armonioso llamado 'felicidad'. La razón que organiza esto se llama prudencia". ${ }^{10}$

La prudencia tiene, para Kang, la virtud de superar el escollo textual contra su tesis que encontramos en la "Observación" al "Teorema III" de la segunda Crítica. Allí, Kant decía que "así como en otros casos una ley natural universal hace todo coincidente, aquí, en cambio, si la máxima [de la felicidad propia] quisiera dar la universalidad de una ley, resultaría directamente la mayor contradicción de la concordancia, el antagonismo más terrible y la aniquilación completa de la máxima misma y de su propósito" $(K p V, 28)$. La piedra de toque de toda la argumentación de Kang y de su conclusión acerca de la fiabilidad de la razón prudencial aplicada a la felicidad radica en que la felicidad propia no es la satisfacción irreflexiva y precipitada de cualquier inclinación que se nos presente. Por el contrario, se trata de la "coincidencia concordante de las inclinaciones naturales en un todo" ( $R G V, 45$, nota, las cursivas son mías). Para elaborar un concepto particular de felicidad que cumpla con el requisito de conseguir una armonía concordante de inclinaciones, necesariamente tenemos que "ponderar no sólo el significado de diferentes inclinaciones y deseos, sino también el resultado de su implementación en el mundo" (Kang 2015, p. 18, las cursivas son mías). En efecto, la razón prudencial no opera ciegamente en el mundo de la praxis, sino que ella misma ya implica ciertas exigencias de (por lo menos) compatibilidad y consistencia cuyo alcance abarca los planos intrasubjetivo e intersubjetivo. En definitiva, la "implementación en el mundo" de un fin cualquiera nos obliga a tener en cuenta el curso de la naturaleza y el comportamiento de los otros. Para la autora, los requisitos involucrados en la estructura de la razón prudencial tendrían la virtud epistémico-práctica de limitar y de neutralizar las posibles con-

${ }^{10} R G V$, 45, nota, las cursivas son mías. Kant asocia la felicidad hedónica con la prudencia también en el "Canon": "Llamo pragmática (regla de la prudencia) a la ley práctica que proviene del motivo de la felicidad; a aquella ley, en la medida en que exista una ley tal, cuyo único motivo es la dignidad de ser feliz, la llamo moral (ley moral)" ( $K r V$, B 834). 
tradicciones entre las diferentes necesidades e inclinaciones en cada sujeto y las posibles contradicciones entre los anhelos de felicidad de los diferentes sujetos ( $c f r$. Kang 2015, p. 19).

Es cierto que la idea de un todo cohesivo de las inclinaciones naturales conlleva un requisito mínimo de compatibilidad. También es correcto que esta compatibilidad funciona como una condición que limita las inclinaciones pre- y extramoralmente "por medio de la razón práctico-técnica (prudencia)" (Kang 2015, p. 19). Pero el problema es que para que la razón prudencial consiga resultados armoniosos, tienen que darse una serie de condiciones fácticas adicionales. Como quedó indicado por Kang, al elaborar un concepto de felicidad propia por medio de la prudencia, tenemos que tener en cuenta su "implementación en el mundo", lo que implica incluir en nuestro cálculo algunas certezas y expectativas adecuadas sobre el curso que tomará la naturaleza, la conducta de los otros y la capacidad de la razón en su uso prudencial en lo que atañe al componente instrumental que este uso involucra. Deberíamos poder contar con algún grado de confianza respecto del devenir de nuestras inclinaciones en un mundo sensible cuya injerencia sobre ellas es determinante. Deberíamos poder contar con algún grado suficiente de certeza de que los demás se comportarán de manera similar a nosotros. Deberíamos, por último, contar con que el uso prudencial de la razón no sólo sea capaz de elaborar el contenido del fin eudaimónico, sino también de determinar con algún grado suficiente de precisión los medios que conducen a él. El inconveniente es que, en Kant, ninguna de estas tres condiciones es real. La objeción central que se plantea a las lecturas de Gauthier y de Kang proviene, entonces, de los presupuestos mismos que debe asumir la idea de un uso prudencial de la razón que tenga una mínima probabilidad de éxito en un mundo atravesado por la contingencia, la inaccesibilidad al curso de la naturaleza y la incertidumbre acerca de cómo se comportarán los demás. Desarrollo este punto en lo que sigue.

Kang distingue la concepción hedonista de la concepción teleológica de la felicidad (cfr. Kang 2015, p. 15). Sin embargo, aunque podamos distinguir analíticamente entre ambas nociones, ellas son inescindibles con vistas a la praxis concreta. Si elaboramos un concepto de la felicidad como un todo organizado de inclinaciones, ello es porque tenemos el propósito de conseguir esa totalidad misma. La felicidad hedonista no tiene sentido por fuera de la vida práctica concreta y, en ella, sólo puede ser entendida eminentemente como un fin de nuestras acciones. Ahora bien, es precisamente por causa de su carácter teleológico que 
la incapacidad de la felicidad para guiar nuestras acciones se vuelve insoslayable.

En un erudito trabajo, Massimo Mori mostró con claridad que el tratamiento kantiano de la felicidad y de su relación con la autonomía se acerca más a las tradiciones francesas y anglosajonas, para las que la felicidad es sensible y terrenal, que a la tradición dominante en Alemania tras la influencia de la tesis leibniziana que subsume la felicidad bajo la rúbrica de la perfección alcanzable por medio de la virtud, cuyo ejercicio depende, a su vez, del acceso intelectual al curso legal de la naturaleza. Mori sostiene que "la crisis del eudaimonismo del siglo XVIII tiene su origen en la separación entre felicidad y autonomía que resulta de la nueva definición kantiana de ambos conceptos" (Mori 1993, p. 34). La relación entre naturaleza y autonomía (o autarquía) es un locus tradicional en el tratamiento filosófico de la felicidad que en la Antigüedad llevó a elaborar el ideal del sabio ataráxico. La tesis de Mori acerca del modo en que Kant reformula radicalmente esta relación se basa en la definición de "felicidad" que Kant da en el § 83 de la Crítica de la facultad de juzgar: "el conjunto de todos los fines posibles por la naturaleza externos e internos a los seres humanos" (KU, 431). Mori resalta correctamente que esto significa que la felicidad hedónica kantiana "no depende del actuar autónomo", sino antes bien "de la beneficencia de la naturaleza" (Mori 1993, p. 34). Pero al mismo tiempo, otra tesis de Kant es que no podemos contar con esa hospitalidad de la naturaleza para ser felices.

En un conocido pasaje del primer capítulo de la Fundamentación, Kant presenta un argumento para mostrar que la felicidad no puede ser el destino (el fin último) de la razón libre. Como el argumento está pensado asimismo para refutar el teleologismo natural del eudaimonismo, parte de una premisa que apela a la economía del diseño de nuestra constitución natural como seres racionales finitos. La premisa, recordemos, establece que "en las disposiciones naturales de un ser organizado, esto es, constituido con finalidad para la vida, presuponemos como principio que no se encuentra en él ningún instrumento para algún fin que no sea el más conveniente y adecuado para él" (GMS, 395). A partir de esta premisa, Kant analiza qué significa para nuestra felicidad el hecho de que tengamos razón y no sólo mero instinto. Su conclusión es que "si en un ser que tiene la razón y una voluntad, el fin propio de la naturaleza fuera su conservación, su bienestar, en una palabra su felicidad, entonces ella habría tomado muy mal sus disposiciones para ello al elegir la razón de la criatura como ejecutora de esa intención suya" (GMS, 395). La explicación que ofrece Kant a continuación la 
encontramos también en la "Introducción" de Naturrecht Feyerabend: el instinto animal tiene reglas naturales confiables en la medida en que no está acompañado de razón práctica ( $c f r$. NRFey, 6). Dado que la felicidad es un asunto natural, el instinto no acompañado de razón pareciera ser una guía mucho más confiable y eficaz para su consecución.

¿Por qué el hecho de que la felicidad no pueda ser el destino de la razón determina su ineficacia para conseguirla? Empecemos por notar que el hecho mismo de que podamos elaborarnos un concepto propio de la felicidad hedónica y empírica y colocarla como un fin de nuestras acciones depende del hecho anterior de que tenemos una razón libre, esto es, del hecho de que podemos considerarnos desde una perspectiva inteligible como actuando de manera independiente de las leyes naturales. Tenemos la capacidad de proponernos fines exclusivamente porque tenemos una razón práctica cuyos usos exceden al meramente prudencial. Así, cuando la felicidad propia se convierte en un fin que hemos elaborado y que nos hemos propuesto, el anhelo natural de la felicidad queda elevado de la mera sensibilidad al plano de la razón práctica.

Ahora bien, esto genera un obstáculo para la satisfacción de este anhelo, precisamente porque la razón, en cuanto que es libre, no nos fue dada junto con un objetivo natural fijo de ser felices de acuerdo con un concepto de la felicidad previamente dado y determinado. Aparece así una especie de paradoja existencial en nuestra condición racional finita. Por nuestra condición misma de seres libres, la razón se encarga de elaborar el concepto de felicidad y entonces nuestro anhelo natural de ser felices empírica y físicamente ya no es en una tarea que podamos cumplir con nuestro instinto. En otras palabras, como la naturaleza no nos da nuestro concepto de felicidad, nuestro instinto natural no juega ningún rol en la satisfacción del anhelo de felicidad, a pesar de que el origen de ese anhelo sea natural. De modo que para Kant el uso de la razón en lo que atañe a la felicidad no se agota con la elaboración y la adopción del fin de la felicidad. Ella también tiene que ocuparse de elegir los medios que conducen a ese fin.

Ahora bien, Kant afirma que la felicidad propia es un fin "cuya posibilidad descansa en condiciones que sólo pueden ser esperadas de la naturaleza" (KU, 433); esto es: los medios para la felicidad propia, en cuanto que es hedónica, están en la naturaleza tanto externa como interna. Ésta es la razón por la cual en el ámbito de la "implementación en el mundo" de nuestro concepto de felicidad debemos contar necesariamente con la beneficencia de la naturaleza. Sin embargo, la naturaleza de la que depende nuestra felicidad hedónica no es consi- 
derable como sistema teleológico que nos sea especialmente benévolo respecto de esa implementación. En el § 83 de la "Doctrina del método de la facultad de juzgar teleológica", Kant es explícito al respecto: "la naturaleza está muy lejos de haber adoptado al ser humano como su preferido particular y de haberlo favorecido con su beneficencia por sobre todos los animales" (KU, 432). El escenario de la naturaleza externa inhóspita se agrava con el hecho de que "la naturaleza en nosotros" nos conduce a males incluso peores que las tormentas y plagas, como la "dominación" y "la barbarie de la guerra" $(K U, 432)$. Si la naturaleza exterior nos fuera beneficiosa, el mal radical nos impediría contar con la colaboración de los demás en nuestros proyectos eudaimónicos. Por estos motivos, Kant concluye que el fin de la felicidad "no sería alcanzado en la tierra en un sistema natural" (KU, 432, las cursivas son mías). La pregunta que surge casi inmediatamente, y que quedará supuesta de ahora en adelante como preocupación de este texto, es: ¿sería el fin de la felicidad empírica alcanzable en un sistema moral? Y dado que el bien supremo no garantiza esta felicidad empírica, ¿podríamos alcanzarla en un sistema moral en el que la felicidad fuera generada por el cumplimiento del segundo deber de virtud?

En conclusión, podemos objetar a Gauthier y a Kang que aunque tengamos una idea racional determinada y clara de la felicidad, el problema de cómo alcanzarla en la práctica no queda resuelto precisamente porque la felicidad propia es también un fin que nos proponemos en un uso de la razón. Podemos elaborar un concepto de la felicidad propia, pero no podemos satisfacer con él nuestro anhelo natural de ser felices en el mundo empírico. Incluso si determinamos hasta el detalle en qué consiste para nosotros la felicidad, lo que Kant niega es que seamos capaces de conseguirla, pues el problema de la implementación es una cuestión de los medios y ellos son siempre dependientes de fuerzas ajenas a nuestro poder. Si la razón, y no un instinto natural que obedece a las reglas del sistema natural, es la encargada de la implementación del fin de la felicidad, entonces nunca podremos satisfacer nuestro anhelo de ser felices. La naturaleza no se acomodará a mi fin si insisto en que ese fin sea mi felicidad.

\subsection{El bien supremo y la felicidad moral}

¿Puede la felicidad entendida como componente del bien supremo garantizar que alcanzaremos nuestro anhelo de ser felices? La respuesta negativa no es controversial. Hacernos dignos de ser felices no garantiza que seamos felices según nuestro concepto propio de la felicidad 
como satisfacción de las inclinaciones y necesidades en un todo organizado. Que la respuesta no sea controversial, sin embargo, significa que la intención de Kant al elaborar la doctrina del bien supremo no fue dar cuenta del anhelo natural de felicidad. La felicidad como componente del bien supremo está diseñada, en las dos Críticas, para cumplir una función moral, no eudaimónica. En otras palabras, la necesidad que satisface el concepto de bien supremo es de tipo moral y no se ve generada por nuestra condición menesterosa del mismo modo en que ella genera nuestro anhelo natural de alcanzar la satisfacción de inclinaciones y necesidades. El hecho de que tanto en la segunda parte del "Canon de la razón pura" de la primera Crítica como en la "Superación crítica de la antinomia de la razón práctica" de la segunda Crítica Kant distinga la felicidad empírica de una felicidad intelectual es una clara indicación al respecto.

En un influyente trabajo, Düsing analizó las diferencias entre los tratamientos del bien supremo en las dos primeras Críticas. Mientras que en el "Canon de la razón pura" la felicidad intelectual como componente del bien supremo tiene la función de posibilitar la ejecución de la ley moral (cfr. Düsing 1971, p. 18), en la segunda Crítica la felicidad intelectual ya no cumplirá este rol. En la primera Crítica, en efecto, Kant establece una conexión de tipo motivacional entre el "mundo moral"11

${ }^{11}$ La tesis de Düsing (1971, p. 18) es que "el bien supremo es, para Kant [en la primera Crítica] un concepto moral del mundo que debe posibilitar la ejecución de la ley moral como un principio a priori" (las cursivas son mías). Esto se puede mostrar a partir de la formulación del imperativo categórico que se diferencia de las fórmulas de la Fundamentación y de la Crítica de la razón práctica. En el "Canon", la fórmula reza: "haz aquello por lo que te vuelvas digno de ser feliz" ( $K r V$, B 836). A pesar de que "la idea de felicidad aquí contenida es superflua e inútil en el principio puro del juicio moral", no resulta completamente inútil en la formulación del imperativo en términos de dignidad de ser feliz en tanto que respuesta a la pregunta por la esperanza: así entendida, "no sólo debe ser considerada como principio de enjuiciamiento, sino también al mismo tiempo como mandato obligatorio que impulsa al cumplimiento moral" (Düsing 1971, p. 18).

La tesis encuentra apoyo textual en que el "mundo moral" es una idea práctica y, como tal, tiene que tener su "influjo" sobre el mundo sensible. El "mundo moral" es definido en términos contrapuestos al mundo natural como "el mundo en la medida en que sea conforme todas las leyes morales (como él puede serlo según la libertad de los seres racionales y debe serlo según las leyes necesarias de la moralidad)" ( $\mathrm{KrV}$, B 836). Este mundo es pensado "meramente como mundo inteligible, porque de él se abstraen todas las condiciones (fines) e incluso todos los obstáculos de la moralidad" ( $K r V$, B 836). Si bien en cuanto que es inteligible es una "mera idea", al ser una "idea práctica", "puede y debe tener su influjo real sobre el mundo sensible para volverlo lo más posible de acuerdo a esta idea" ( $K r V, \mathrm{~B} 836)$. La "realidad 
y la respuesta a la pregunta acerca de la esperanza de participar de la felicidad si nos hemos comportado de modo de no ser indignos de ella. Sin embargo, la felicidad en cuestión no es tal que podamos obtenerla en un sistema natural, sino sólo en la idea práctica de un "sistema de la moralidad" (B 837), con el que la felicidad está enlazada "pero sólo en la idea de la razón pura" (B 837). Para pensar este mundo moral, debemos hacer abstracción de todas las inclinaciones en cuanto obstáculos a los que se opone la intención virtuosa (B 837). Como parte de una religión moral, la esperanza en la felicidad distribuida acorde al merecimiento nos demanda, así, abstraer nuestro concepto de felicidad propia entendida como satisfacción de un todo organizado de inclinaciones. Con todo, no se trata todavía de la felicidad moral como contento consigo mismo por la conciencia de la intención virtuosa.

En la segunda Crítica, la felicidad como elemento constitutivo del bien supremo es definida en estos últimos términos. Aquí, se trata de resolver la antinomia que atañe a la relación causal entre felicidad e intención moral virtuosa. Mientras que la proposición de que la felicidad empírica puede ser fundamento moral de determinación es absolutamente falsa, la tesis que conecta la intención virtuosa con la felicidad es falsa sólo bajo la condición de que pensemos esa causalidad exclusivamente en el mundo sensible. La relación entre la intención moral virtuosa y la felicidad puede ser una conexión "mediata (por medio de un autor inteligible de la naturaleza)" y "necesaria" sólo cuando nos pensamos como no existiendo exclusivamente "en una naturaleza que sea mero objeto de los sentidos" (cfr. KpV, 114-115). Ahora bien, ¿dónde debemos pensar esta conexión y de qué tipo de felicidad se trata? Aquí Kant introduce la noción de felicidad moral como distinta de la "felicidad (llamada impropiamente) estética, que descansa en la satisfacción de las inclinaciones" $(K p V, 118)$. Se trata de una felicidad

objetiva" de esta idea permite responder la pregunta de la esperanza de participar de la felicidad por el merecimiento en la medida en que relaciona la ley moral con esa esperanza en una suposición del "uso teórico" de la razón, "sólo en la idea de la razón pura" ( $K r V$, B 837). La idealidad del bien supremo, no obstante, tiene en el "Canon" un explícito rol asociado a la motivación moral: "Es necesario que nuestra entera conducta moral esté subordinada a máximas morales; pero es al mismo tiempo imposible que esto ocurra si la razón no liga con la ley moral, que es una mera idea, una causa eficiente que determine para el comportamiento acorde a la ley moral un resultado que se corresponda exactamente con nuestros fines supremos, sea en esta o en otra vida. Por lo tanto, sin un Dios y sin un mundo para nosotros ahora invisible pero esperado, las ideas soberanas de la moralidad son ciertamente objetos de aprobación y admiración, pero no motivos impulsores del propósito y del ejercicio" ( $K r V$, B 840-841, las cursivas son mías). 
"intelectual" que, como "contento consigo mismo", "no indica un goce como el que caracteriza la felicidad, pero sí un bienestar en la existencia propia, un análogo de la felicidad, que tiene que acompañar necesariamente la conciencia de la virtud" ( $K p V, 117$, las cursivas son mías). Esta satisfacción en la conciencia de la intención virtuosa es, contrariamente a la felicidad hedónica, "sólo un bienestar negativo en la propia existencia, en el cual uno es consciente de no necesitar nada" ( $K p V, 117)$. El contenido de este goce negativo es la conciencia de nuestra libertad en cuanto capacidad de "seguir la ley moral" con "independencia de las inclinaciones, por lo menos como móviles determinantes (si bien no como afectantes) de nuestro apetecer" $(K p V, 117)$. Cuando tenemos conciencia de haber actuado de tal modo, el sentimiento de "contento invariable necesariamente unido a ella" no es, a diferencia de los sentimientos involucrados en la felicidad física, "particular" (cfr. KpV, 117).

Se desprende de estas indicaciones textuales que las funciones que cumple la felicidad como componente del bien supremo no son, en ninguna de las dos primeras Críticas, propiamente eudaimónicas, en el sentido de que sus roles no son satisfacer el anhelo natural de ser felices según el concepto de felicidad propia elaborado a partir de la sensibilidad. ${ }^{12}$ Asimismo, la felicidad como componente del bien supremo tratado en la primera Crítica como objeto de esperanza se distingue también de la felicidad moral según es entendida en la segunda Crítica, noción que Kant incluye finalmente en la perfección propia. ${ }^{13}$ En efecto,

${ }^{12}$ Mori (1993, p. 35) afirma correctamente que si atendemos a las fuentes, vemos que Kant "oscila entre negar y reconocer" que pueda existir "una felicidad puramente moral": "Esto lleva a Kant a definir la felicidad a veces con expresiones que están muy cerca de la tradición platónica: la moralidad no sólo hace a los seres humanos 'dignos' sino también 'capaces' de felicidad [cfr. Refl. 7202, XIX, 276 y ss.]. La resolución definitiva consistirá en todo caso en que la 'felicidad moral' se proyecta en el futuro —una felicidad moral que en $R G V$ es definida como 'garantía [...] de la realidad y la constancia de una intención moral interna que continuamente se mueve en el bien' $[R G V, 67]$. En este tipo de felicidad ve Kant en la $K p V$ —donde se la llama 'Seligkeit' - un 'objeto de la esperanza' en el marco de la doctrina de un bien supremo que Kant considera una exigencia inevitable de la razón, aunque esto no carece de dificultades conceptuales. Definida como objetivo escatológico-religioso, la felicidad ya no tiene que ver en todo caso con la situación aquí y ahora de los seres humanos y por lo tanto no pertenece a la determinación de esa felicidad que el ser humano individual se pone como su objetivo natural".

${ }^{13}$ Se distinguen dos tipos de felicidad no empírica: la intelectual como parte componente del bien supremo (la felicidad por el merecimiento) y la felicidad moral como satisfacción con uno mismo (la felicidad como conciencia de tener intenciones morales virtuosas en todo momento). La distinción anterior entre felicidad física e intelectual aparece en varios lugares del corpus kantiano. En una anotación 
Kant critica abiertamente el uso impropio del giro "felicidad moral" y ello tiene un significado especial para su tratamiento del deber de la felicidad ajena. Esto nos lleva a la sección siguiente.

\section{3. ¿Podemos hacer felices a los demás?}

En el "Prologo" a la Doctrina de la virtud, Kant afirma que la idea de "una cierta felicidad moral que no descansa en causas empíricas" es "un absurdo contradictorio en sí mismo" (MS, 377). Negar que exista una felicidad stricto sensu que no descanse en causas empíricas es el punto de partida con el que Kant introduce la doble relación del concepto de "deberes de virtud" con la perfección y la felicidad, por un lado, y con los deberes consigo mismo y para con los demás, por el otro. En efecto, cuando en la sección V.B de la "Introducción" examina el concepto de la felicidad ajena como fin que es deber, Kant vuelve sobre la distinción entre felicidad "moral" y "física". Aquí, Kant retoma las tesis de que "desear para uno y buscar la felicidad, esto es, el contento con el propio estado en la medida en que uno tiene la certeza de que durará, es inevitable para la naturaleza humana" (MS, 387) y de que esta naturalidad de la felicidad propia determina que no pueda ser tomada como un fin que es deber. La pregunta que queda tácitamente planteada es qué tipo de felicidad sí puede ser tomada como deber.

En este marco, Kant retoma su crítica a la idea de una felicidad moral, entendida como "el contento con la propia persona y el propio comportamiento moral, por lo tanto, con lo que uno hace" (MS, 387), para descartar que ella sea el objeto del deber en cuestión. La razón por la que esta supuesta felicidad no puede ser el objeto del deber analizado consiste en que es un "modo de sentir" ( $M S, 387)$ que pertenece a la

a los Initia de Baumgarten (fase ípsilon), Kant distingue entre la "verdadera felicidad" o "felicidad del mundo intelectual", que es "en sí misma como un efecto del libre arbitrio de seres racionales", esto es, que se puede alcanzar "por medio de acciones orientadas a sí mismo o recíprocamente hacia otros", y la felicidad que es "un meramente contingente y dependiente externamente de la naturaleza" (Refl. 6907, XIX, 202). El primer tipo de felicidad es, en esta fuente temprana, inmediatamente equiparado con la "perfección moral" que "se procura en una felicidad tal que sólo descansa en la voluntad", de modo que "tengo que buscar el modelo de la perfección en un mundo bueno posible de alcanzar por mi parte" (Refl. 6907, XIX, 202-203). En la Religión dentro de los límites de la mera razón, la felicidad "física" se define como "la garantía de una posesión perpetua del contento con el estado físico propio (estar libre de males y el goce de un placer siempre creciente)" (RGV, 67). La felicidad "moral" es definida como la "realidad y tenacidad de una intención moral siempre que mueve siempre al bien y nunca cae fuera de él" $(R G V, 67)$. 
propia perfección, pues "quien debe sentirse feliz en la mera conciencia de su rectitud ya posee aquella perfección que en el título anterior fue definida como aquel fin que es a la vez deber" ( $M S$, 388). Para llegar a la conclusión buscada, esto es, qué tipo de felicidad puede ser objeto de un deber de virtud, Kant descarta en primer lugar la candidatura de la felicidad moral. Queda, así, sólo la felicidad física como candidata. La felicidad física, aquella que deseamos naturalmente y que no puede ser objeto de un deber para con uno mismo, es entendida aquí como "el contento con lo que la naturaleza nos depara, por lo tanto, con lo que se disfruta como un don de otro" (MS, 387). Como quedó rechazado que la felicidad propia pueda ser objeto de un deber para consigo mismo, se sigue que sólo la felicidad física de los otros puede ser el contenido del segundo deber de virtud: "Por lo tanto, cuando se trata de aquella felicidad que debe ser deber procurar como un fin mío, la felicidad tiene que ser de otras personas, cuyo fin (permitido) yo hago con ello también mío" (MS, 388).

Kant es claro respecto de qué tipo de felicidad debemos procurar para los demás: "No puedo hacer el bien a nadie según mis conceptos de la felicidad [...], sino que según los conceptos de aquel a quien pienso dispensar un beneficio" (MS, 454). Se trata del concepto propio de felicidad que los otros han elaborado, según la noción hedónica de felicidad que hemos visto. La pregunta que se plantea aquí es: ¿afectan los problemas de implementación que afectaban a la felicidad propia a la hora de cumplir este deber? En la Doctrina de la virtud, Kant no se detiene a analizar este problema, pero no podemos pasarlo por alto porque, nuevamente, se trata del mismo tipo de felicidad y ultra posse nemo obligatur. ${ }^{14}$ Dado el panorama que quedó trazado hasta aquí, mi tesis es que para resolver el problema que plantea el anhelo natural de

${ }^{14}$ Las cuestiones de implementación que Kant sí reconoce están asociadas a la amplitud del deber, en cuanto que, como deber de virtud, nos obliga a la adopción de una máxima de fines y no a acciones precisas: cómo descarguemos nuestro deber de la felicidad ajena dependerá de qué consideren los demás que es su felicidad, de que sea permisible ( $c f r . M S, 388$ ), de las relaciones personales que tengamos con ellos, si hemos de decidir entre ayudar a un desconocido o a nuestro amigo (cfr. $M S$, 452) y hasta dónde podemos hacer felices a los demás sin que ello acarree nuestra ruina personal ( $c f r$. $M S, 388$ ). Así, la determinación específica del modo en que descarguemos el deber depende de las circunstancias y también de nuestra subjetividad, pero no encierran un problema filosófico, sino que dan cuenta de la sensibilidad de la ética de Kant respecto de la complejidad de la vida moral concreta. Asimismo, aunque no es tema para desarrollar en este trabajo, el tipo de argumentación práctica que se pone en juego en estos casos no es instrumentalprudencial, sino que se trata de sopesar máximas. 
ser felices, es necesario colocar la felicidad en el ámbito que sí podemos tener bajo nuestro control, el mundo de la práctica moral. La felicidad ajena como deber tiene la ventaja de ubicarse al mismo tiempo en las dos perspectivas en las que nos consideramos, a diferencia de la felicidad empírica propia (sistema natural) y la felicidad moral o intelectual (mundo intelectual). Así, existe un modo de salvar al menos uno de los problemas de implementación que hemos mencionado. Si bien la implementación de la felicidad en el mundo no quedará resuelta de manera absoluta, el deber de la felicidad ajena reconduce la felicidad empírica al sistema moral, algo que ni la noción moral de la felicidad ni la felicidad como componente del bien supremo conseguían hacer. Esta solución se encuentra en el contenido mismo del segundo deber de virtud.

Los deberes de virtud se derivan normativamente del "principio supremo de la doctrina de la virtud", que reza "actúa según una máxima de fines tales que tenerlos pueda ser una ley universal para cada uno" $(M S, 395)$. Kant explica que este principio implica que "no es suficiente con que el ser humano no esté autorizado a usarse a sí mismo y a los demás meramente como medio (con ello puede ser indiferente para con ellos), sino que proponerse al ser humano en general como fin es en sí mismo un deber del ser humano" (MS, 395). A partir de este principio, los deberes de virtud son entendidos como fines que son al mismo tiempo deberes, esto es, como fines que es un deber para nosotros adoptar en nuestra libertad interna. Ahora bien, ¿qué hacemos en nuestra libertad interna, en nuestra conciencia moral, cuando nos proponemos hacer felices a los demás? Por empezar, al proponerme al otro como fin lo reconozco como fin en sí mismo desde la perspectiva nouménica por la que nos consideramos libres. Pero al asociar esta proposición del otro como mi fin con el deber de hacerlo feliz según su propio concepto de felicidad, al mismo tiempo lo reconozco como ser racional finito, como una persona con una subjetividad particular determinada e irreductible a cualquier otra que, además, necesita ser feliz.

En la segunda parte de la "Doctrina de los elementos" de la Doctrina de la virtud, Kant detalla los "deberes de amor"15 que, junto con los "deberes de respeto", conforman el conjunto de los deberes de virtud para con los demás. Me concentraré en los primeros, en tanto que bajo ellos se encuentran los deberes de beneficencia. Del análisis del tratamiento kantiano de estos deberes se desprende que el ejercicio de

${ }^{15}$ Los deberes de amar al prójimo se dividen en deberes de beneficencia, de gratitud y de simpatía (MS, 452). Véase Horn 2008 para un buen estudio del amor benevolente en la ética de Kant.

Diánoia, vol. LXII, no. 78 (mayo de 2017). 
la beneficencia, cuando es motivado moralmente por fin de la humanidad, genera en este mundo y en el presente una de las condiciones de posibilidad para la felicidad natural anhelada, a saber, la predisposición moral a la asistencia recíproca efectiva. Esta condición no está garantizada por la naturaleza, sino que es algo que nosotros instauramos en el mundo empírico por medio del ejercicio de nuestros deberes de virtud.

Los deberes de amor y de respeto al prójimo, respectivamente, se diferencian en que el primero es un tipo de deber positivo que nos demanda realizar una serie de acciones, mientras que el segundo es un deber negativo en el sentido de que nos demanda omitir tratar a los demás como medios. ${ }^{16} \mathrm{El}$ "deber de amar al prójimo" es definido como "el deber de hacer míos los fines de los otros (en la medida en que no sean inmorales)" (MS, 450). Es claro que con esto Kant no quiere decir que debamos convertir los fines de los demás en fines que tenemos que conseguir para nosotros: los hacemos nuestros para fomentar que los otros puedan alcanzarlos. Este deber de hacer míos los fines de los otros, como ya adelantaba la aclaración parentética en la explicación del principio supremo de la doctrina de la virtud, nos demanda una "benevolencia activa" (cfr. $M S$, 452). En efecto, el deber de amor al prójimo, si ha de incluir el deber de beneficencia, no puede tratarse meramente de una "benevolencia en el deseo", porque ello es tan sólo una "simple complacencia en el bien del otro sin tener que contribuir uno mismo en algo para ello (cada uno para sí; Dios para todos nosotros)" (MS, 452). Si lo debido fuera este sentimiento, podríamos ser completamente indiferentes en la práctica, dejar que cada uno busque su felicidad en la Tierra, mientras los respetemos y no los tratemos como medios, y tener la esperanza de que cada uno participará de la felicidad acorde a su merecimiento en un mundo inteligible.

En este marco, Kant se plantea la pregunta acerca de "¿cómo puede, además de la benevolencia para con otros seres humanos en el deseo (lo que no cuesta nada), todavía requerirse que ésta sea práctica, es decir, requerirse la beneficencia para con los necesitados como deber para quien tenga la capacidad de hacerlo?" $(M S, 452)$. La respuesta comienza por distinguir nuevamente entre la benevolencia como "placer en la felicidad (el bienestar) de los demás" y la beneficencia, enten-

\footnotetext{
${ }^{16}$ Podemos considerar al "deber de respeto a mi prójimo" como negativo pues consiste en adoptar "la máxima de no despreciar a ningún otro ser humano convirtiéndolo en mero medio (no demandar que el otro deba venderse a sí mismo para entregarse a mi fin)" de modo que al cumplir con este deber, "me mantengo dentro de mis límites de no quitarle nada al otro del valor que él está autorizado a darse a sí mismo como ser humano" ( $M S, 450)$.
} 
dida como "benevolencia activa, práctica, de proponerse el bien y la salud del otro como fin (hacer el bien)" (MS, 452). En cuanto deber de virtud derivado del principio supremo de la doctrina de la virtud, la beneficencia nos demanda adoptar la máxima de fines de "proponerse uno mismo esto como fin" ( $M S, 452)$. En el $\S 30$ de la Doctrina de la virtud, esta máxima es formulada también como "la máxima del interés común" y Kant explica por qué este interés común "es deber universal de los seres humanos" (MS, 453). La justificación normativa discurre aquí en un primer momento en los términos de la felicidad propia, lo que no es sorprendente dado que se trata de fundamentar la beneficencia como una máxima que es de interés común [gemeinnützige Maxime] contrapuesta a la máxima del mero autointerés egoísta [eigennützige Maxime]. De un modo similar al de la línea argumentativa que Kant usó en la Fundamentación para establecer el deber amplio para con los demás a partir de la formulación legaliforme del imperativo categórico, se explica que:

Hacer el bien, esto es, ser activos en conducir a otros seres humanos en necesidad a su felicidad sin esperar nada por ello y según se sea capaz, es un deber de todo ser humano. Pues todo ser humano que se encuentra en necesidad desea ser ayudado por otros seres humanos. Pero si hace pública su máxima de no querer prestar por su parte asistencia a los demás en su necesidad, es decir, si la convirtiera en una ley permisiva universal, entonces cuando él mismo estuviera en necesidad, todos le negarían su asistencia del mismo modo, o por lo menos estarían autorizados a negársela. Por lo tanto, la máxima misma del autointerés se contradice consigo misma cuando se la intenta hacer ley universal, esto es, es contraria al deber. (MS, 453, § 30)

Con todo, esta línea argumentativa que descansa en el autointerés desemboca en una idea intrínsecamente moral: ${ }^{17}$ "En consecuencia, la máxima del interés común, la beneficencia para con los necesitados, es deber universal de los seres humanos porque ellos han de considerarse como semejantes, como seres racionales necesitados, reunidos por la naturaleza en una morada para la ayuda recíproca" (§ 30).

La relación entre la justificación de la máxima de la beneficencia en términos de la autocontradicción que encierra el autointerés (la imposibilidad de universalizarlo), por un lado, y en términos del reco-

17 "Esta línea argumentativa", no la ética kantiana en su totalidad. No afirmo tal cosa en ningún lugar de este texto — ni la afirmaría-. Agradezco al segundo dictaminador por instarme a hacer esta aclaración. 
nocimiento moral de los semejantes, por el otro, se cifra en ese reconocimiento moral mismo que ocurre cuando nos proponernos a los demás como fines. Me refiero a que esta comunidad de ayuda recíproca sólo es posible una vez que nos consideramos a nosotros y a los demás como seres a la vez racionalmente libres y menesterosos. Así, la máxima de la beneficencia tiene su piedra de toque en la tesis de que vivimos en un mundo natural que no es benevolente para con nosotros y que por ello, para que se satisfaga el anhelo natural de la felicidad, debemos y podemos fundar una comunidad moral en la que la ayuda mutua hace que la felicidad empírica se vuelva posible en la Tierra.

Proponernos a los demás como fines ¿alcanza para hacerlos felices? La felicidad ajena sigue siendo una cuestión cuya problematicidad mantiene los inconvenientes de la felicidad propia: se sigue tratando de la felicidad propia, con todos sus problemas de implementación, aunque sea la felicidad propia de los otros, principalmente porque debemos hacerlos felices según sus conceptos de la felicidad y no según lo que nosotros pensamos que deberían desear. Así como dudamos acerca de qué nos hará felices a nosotros, los otros también dudan al respecto y nosotros también dudaremos acerca de qué medios podrán promover sus fines. Si los demás no pueden determinar con certeza, al igual que nosotros respecto de nuestra felicidad propia, qué medios conducen al fin de la felicidad, ¿cómo podemos determinarlo nosotros respecto de ellos? Quizás no se pueda resolver este problema en las fuentes kantianas. No obstante, esto no lleva a Kant a desesperar acerca de la posibilidad de que seamos felices en este mundo. Que Kant no recae en un escepticismo extremo al respecto queda indicado, por ejemplo, en este pasaje, en el que el deber de ser partícipes activos en el destino de los demás es conectado con los sentimientos de simpatía moral:

Si bien sufrir y alegrarse con los demás no es en sí mismo un deber, sí lo es participar activamente de sus destinos. Para ello, es deber indirecto cultivar los sentimientos compasivos naturales (estéticos) en nosotros y utilizarlos como tantos otros medios para la simpatía basada en principios morales y los sentimientos correspondientes a ellos. - Por lo tanto, es deber no esquivar los lugares en los que se encuentran personas pobres a los que les falta lo más necesario, sino buscar esos lugares; no rehuir de las salas de los enfermos o de las prisiones de los deudores, etc., para evitar la dolorosa simpatía que no se puede reprimir. Porque ella es uno de los impulsos que la naturaleza ha puesto en nosotros para que hagamos aquello para lo que la sola representación del deber no es suficiente. (MS, 457, las cursivas son mías) 
4. Conclusión

El deber de beneficencia funda una condición necesaria para la consecución de la felicidad. Puesto como deber, el fin de los seres humanos consigue trasladar la felicidad terrenal al reino moral de un modo en el que incluso la noción de "bien supremo" no consigue hacerlo. El deber de la felicidad ajena descubre un ámbito de relación con el otro en el que la dignidad de la humanidad organiza, en la práctica concreta de la moralidad, las relaciones interpersonales por medio de la preocupación por la felicidad del otro. Asistir a los demás en la persecución de sus ideas de la felicidad como un todo coherente (cuando ese fin es permisible, como aclara Kant) es una tarea moralmente necesaria que también surge del reconocimiento de que el anhelo de la felicidad es ineludible para nosotros, en cuanto seres racionales finitos. Que la felicidad ajena sea nuestro deber nos obliga a reconocer a los otros seres humanos como seres racionales finitos que no pueden renunciar a su anhelo de ser felices. Así, la felicidad propia de los otros, convertida en deber, eleva a un ámbito propiamente moral ese anhelo que tenemos de modo meramente natural, y lo hace de un modo más exitoso que la felicidad entendida como parte del bien supremo y como satisfacción en la conciencia moral, pues no la convierte en algo a esperar en un mundo inteligible futuro ni en perfección virtuosa: la mantiene en el mundo terrenal, aquí y ahora. ${ }^{18}$

\section{BIBLIOGRAFÍA}

Darwall, S.L., 1985, "Kantian Practical Reason Defended", Ethics, vol. 96, no. 1, pp. 89-99.

Düsing, K., 1971, "Das Problem des höchsten Gutes in Kants praktischer Philosophie", Kant-Studien, no. 62, pp. 5-42.

Gauthier, D., 1985, "The Unity of Reason: A Subversive Reinterpretation of Kant", Ethics, vol. 96, no. 1, pp. 74-88.

Horn, Ch., 2008, “The Concept of Love in Kant's Virtue Ethics” en M. Betzler, (comp.), Kant's Ethics of Virtue, Walter de Gruyter, Berlín, pp. 147-173.

${ }^{18}$ Para elaborar este artículo conté con el apoyo financiero del CONICET y del proyecto PICT 2014-0669, ANPCyT (Argentina), que dirijo. Una versión previa de este trabajo fue leída como conferencia en el marco del seminario C.L.A.S.I.C.O.S., IFS, CSIC Madrid, en junio de 2016. Agradezco especialmente a Nuria Sánchez Madrid, Amanda Núñez, Roberto Aramayo y Alejandro Alba por los comentarios que me hicieran en esa oportunidad. También agradezco a las/los dictaminadoras/es anóminos de Diánoia por sus valiosos aportes.

Diánoia, vol. LXII, no. 78 (mayo de 2017). 
Kang, J.Y., 2015, Die allgemeine Glückseligkeit. Zur systematischen Stellung und Funktionen der Glückseligkeit bei Kant, Walter de Gruyter (Kant-Studien Ergänzungshefte, 184), Berlín.

Kant, I., Gesammelte Schriften, Preußische Akademie der Wissenschaften, Berlín, 1900 y ss.

—, KrV, Kritik der reinen Vernunft, en Gesammelte Schriften, tomo IV, pp. 1252.

_- GMS, Grundlegung zur Metaphysik der Sitten, en Gesammelte Schriften, tomo IV, pp. 385-463.

—, KpV, Kritik der praktischen Vernunft, en Gesammelte Schriften, tomo V, pp. 1-163.

- KU, Kritik der Urteilskraft, en Gesammelte Schriften, tomo V, pp. 165485.

— aber nichts für die Praxis, en Gesammelte Schriften, tomo VIII, pp. 273-314.

- $R G V$, Die Religion innerhalb der Grenzen der bloßen Vernunft, en Gesammelte Schriften, tomo VI, pp. 1-102.

—, MS, Die Metaphysik der Sitten, en Gesammelte Schriften, tomo VI, pp. 205-493.

- Refl., Reflexionen aus dem Nachlaß: Moral-, Rechts- und Religionsphilosophie, en Gesammelte Schriften, tomo XIX.

—- NRFey, 2010, Naturrecht Feyerabend. Einleitung. Neue, revidierte Fassung, en H.P. Delfosse, N. Hinske y G.S. Bordoni, Kant-Index. Band 30: Stellenindex und Konkordanz zum "Naturrecht Feyerabend". Teilband 1: Einleitung des "Naturrechts Feyerabend", Frommann-Holzboog, Stuttgart, pp. 1-15.

Kienzle, B., 2007, "Macht das Sittegesetz unglücklich?”, en U. Kern, Was ist und was sein soll. Natur und Freiheit bei Immanuel Kant, Walter de Gruyter, Berlín, pp. 267-284.

Mori, M., 1993, "Glück und Autonomie. Die deutsche Debatte über den Eudämonismus zwischen Aufklärung und Idealismus", Studia Leibnitiana, vol. 25, no. 1, pp. 27-42.

Rivera Castro, F., 2014, Virtud, felicidad y religión en la filosofía moral de Kant, Instituto de Investigaciones Filosóficas-UNAM, México. 